\title{
Multi-Objective Optimization of Turning Process during Machining of AISI 1025 on CNC machine Using Multi-objective particle swarm optimization H. E. Radhi ${ }^{1 *}$, Mohammed jammel alsalhy ${ }^{2}$
} Available at http://jeng.utq.edu.iq engjrnal@jeng.utq.edu.iq

\begin{abstract}
Parametric optimization of the transformation process is a task of improving multiple objectives. In general, no single set of input parameters can provide the best hardness of the metal and the best finish of the surface at the same time. While when using the genetic algorithm proved that it is possible to obtain more than one goal of the function at the same time. In the current research the use of Multi-objective particle swarm optimization (MOPSO) to determine the best hardness of the metal and less roughness of the surface operator at the same time. A mathematical model was also developed to predict the hardness of the metal and surface roughness using Taguchi technology depending on the input variables (cutting speed, cutting depth and feeding rate). Experiments were conducted on a CNC machine in turning carbon steel AISI 1025 using carbide cutting tool. It was found that the most influential factor on the surface roughness is the feeding rate, while the most important effect on the hardness is the cutting speed.
\end{abstract}

\section{Keywords: Surface roughness (Ra), Hardness (Ha), MOPSO, mode FRONTIER, Optimization.}

\section{Introduction}

As a result of the rapid development today in the procedure of manufacturing industries, the process of applying metal improvement techniques to the parameters of the pieces is important. This type of carbon steel is known as mild steel (Medium carbon steel) and $0.25 \% \mathrm{C}$ has wide range of the applications in electrical devices, construction of pipelines, products, construction as structural steel, car manufacturing industry, railway parts also used in manufacturing doors, windows, tanks, tanks, post boxes and in manufacturing some auto parts.

There are several parameters have an important influence on surface roughness and hardness as cutting speed, feeding rate and cut depth. Determining the appropriate values for these parameters will result in good surface quality and in less time [1].

Neural networks, fuzzy logic, MOPSO and genetic algorithm (GA) are effective methods which are used for the optimization of these parameters. E. A. Rahim et al [2] studied the impact of cutting factors (cutting speed, depth of cutting and feed rate) on tool wear and roughness of the surface during turning steel AISI 8620. Using the cutting tools of the ceramic materials, the tests were performed without the use of coolant (Dry operation). It was observed from the results that performance wear increases with increasing feeding rate, depth of cutting and cutting speed, while roughness of the surface decreases by increasing input parameters. Palanikumar K. [3] developed a mathematical model using a surface response methodology (RSM) to predict the surface roughness of the surface to connect the cutting parameters during machining of GFRP composites. Cutting speed, feeding rate and depth of cutting were introduced as input variables. After analyzing the impact of the input parameters on the roughness of the surface on the basis of the mathematical model it was observed that surface roughness increases with increasing feeding rate and angle of fiber direction while decreasing with increasing depth of cutting and cutting speed.. Sravanakumar et al [4] investigate the influence of machining process parameters as feeding rate, cutting speed, and cutting depth on the output parameters such as metal removal rate (MRR) and surface roughness. It was noted from the results that the best value for the metal removal rate is 2122.23 $\left(\mathrm{mm}^{\mathrm{a}} / \mathrm{min}\right.$ ) when cutting conditions were (cutting speed $(79.99 \mathrm{~m} / \mathrm{min})$, feed rate $(0.25 \mathrm{~mm} / \mathrm{rev})$ depth of cut $(0.1 \mathrm{~mm}))$; and less surface roughness when input parameters (cutting $79.9(\mathrm{~m} / \mathrm{min})$, feeding rate 0.15 $(\mathrm{mm} / \mathrm{rev})$, depth of cut $(0.1 \mathrm{~mm}))$. N. Satheesh Kumara et $a l,[5]$ investigate the influence of both the feeding rate and the speed of cutting on surface roughness during the turning of carbon steel. Five kinds of different carbon steel alloys were turning by CNC machine using carbide cutting tool. The carbon alloys were EN8, SAE8620, EN24, EN19 and EN47. It was observed from the results that surface roughness decreases with increasing cutting speed while the roughness increases with increased feeding rate for all alloys in this search. G. Harinath Gowd et al [6] studied the impact of input variables (spindle speed, feeding rate and depth of cut) on metal removal rate (MRR) and tool wear in turning AISI S2 using the carbide tools on machine CNC. The operation of samples in the test using coolant condition. It was noted through the drawings that MRR increases with increasing the spindle speed, depth of cutting and feeding rate, while the tool wear increase with increasing spindle speed but the increase was simple while the increase was significant when increasing feeding rate and depth of cutting.

Murat S. and Abdulkadir G. ,[7] studied the influence of input parameters (feed rate, cutting speed and cutting 
depth and cooling conditions) on surface roughness (Ra, $\mathrm{Rz}$ ) in turning AISI1050 steel by using (CNC) turning machine running test samples was under dry conditions, wet operation and minimum quantity lubrication (MQL). A methodology surface response and the design of taguchi were used to find the optimum parameters for cutting and developed mathematical model for prediction for $\mathrm{Rz}$ and $\mathrm{Ra}$. It was noted from the results that feeding rate was the maximum effective factor on the roughness of the surface and MQL was the best conditions that improve surface roughness. R. Hameed and H. Maath, [8] developed two mathematical models to predict surface roughness $(\mathrm{Ra})$ and tool temperature in terms of spindle speed, depth of cutting and feeding rate. Lab fit software was used to achieve these equations. AISI 1045 steel was the workpiece material in the turning process with carbide cutting tools. Genetic Algorithm (Ga) was used to reach the optimum cutting conditions. The results showed that (Ra) decreases with increasing spindle speed, and depth of cutting but increases with increased feeding rate while tool temperature increases with cutting parameters (spindle speed, feeding rate and cut depth).

This study is very important to evaluate the optimization of the parameters of the pieces represented by cutting tools, cutting speed, depth of cutting and feeding rate during the turning of carbon steel AISI 1025 on the CNC lathe. Using Minitab software (Taguchi method) and analysis the variance in (ANOVA).

In the present study, the influence of cutting parameters on the output will be examined to find the optimal cutting conditions using the MOPSO in modeFRONTIER software. The study shall be in the case of wet and dry conditions for the purpose of knowing the influence of the presence of coolant on the process.

\section{Expermintal Work}

As a result of the extensive development of industrial cutting and machining machines, manufacturing processes must be carried out with high accuracy, time and cost. In the current work, samples of experiments were run on a CNC machine because they provide precision when operating as in figure 1 . Several tests were carried out on the extracted samples. The surface roughness was measured using the roughness measurement device shown in Figure 2. Rockwell hardness was also measured using the device shown in Figure 3.

The workpieces were cleaned before testing by removing the thickness of the upper surface in order to eliminate any surface defects. 25 pieces of equal length 10 $\mathrm{mm}$ were marked on workpieces. The surface roughness of the surfaces operated using a roughness-type testing device (PCE-RT 1200) and hardness was measured. Experiments were designed using (L25) Taguchi orthogonal array. Table 1 shows the machining parameters and their levels. The experimental design and observed values of responses are shown in table. Table 2 Taguchi orthogonal array with observed values.

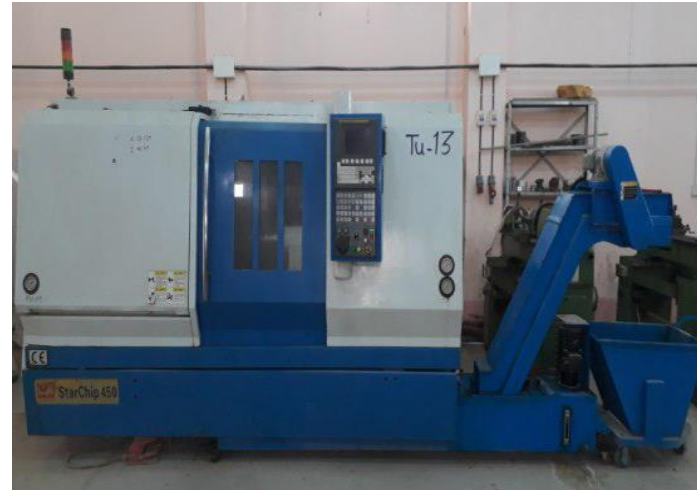

Fig. 1 CNC turning machine of FANUC (Series Oi Mate-

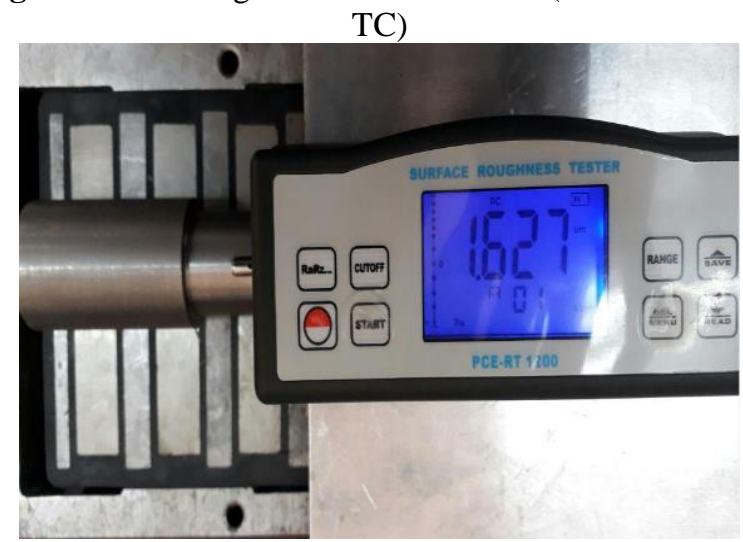

Fig. 2 surface roughness measurement with (a roughnesstype testing device (PCE-RT 1200).

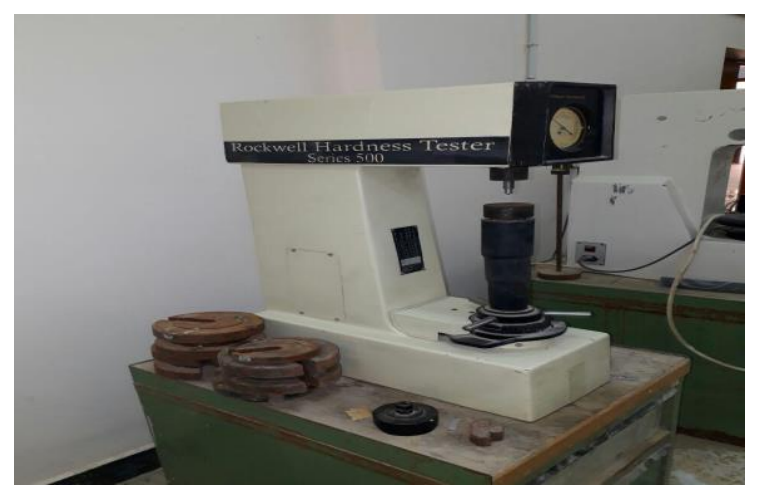

Fig. 3 Rockwell device for measuring hardness.

Table 1 Machining parameters with their levels.

\begin{tabular}{|c|c|c|c|}
\hline Level & $\begin{array}{c}\text { Cutting speed } \\
(\mathrm{mm} / \mathrm{min})\end{array}$ & $\begin{array}{c}\text { Feed rate } \\
(\mathrm{mm} / \mathrm{rev})\end{array}$ & $\begin{array}{c}\text { Depth of } \\
\text { cut(mm) }\end{array}$ \\
\hline 1 & 107.44 & 0.01 & 0.5 \\
\hline 2 & 141.37 & 0.05 & 1 \\
\hline 3 & 175.31 & 0.1 & 1.5 \\
\hline 4 & 209.23 & 0.2 & 2 \\
\hline 5 & 243.16 & 0.3 & 2.5 \\
\hline
\end{tabular}


Table 2 Taguchi orthogonal array with observed values.

\begin{tabular}{|c|c|c|c|c|c|}
\hline No. & $\begin{array}{c}\text { Cutting } \\
\text { speed } \\
(\mathrm{mm} / \mathrm{min})\end{array}$ & $\begin{array}{c}\text { Feed rate } \\
(\mathrm{mm} / \mathrm{rev})\end{array}$ & $\begin{array}{c}\text { Depth } \\
\text { of } \\
\text { cut(mm) }\end{array}$ & $\begin{array}{c}\text { Ra } \\
(\mu \mathrm{m})\end{array}$ & Hard. \\
\hline 1 & 107.44 & 0.01 & 0.5 & 1.282 & 38.7 \\
\hline 2 & 107.44 & 0.05 & 1 & 1.551 & 38.4 \\
\hline 3 & 107.44 & 0.1 & 1.5 & 1.847 & 38.6 \\
\hline 4 & 107.44 & 0.2 & 2 & 2.072 & 37 \\
\hline 5 & 107.44 & 0.3 & 2.5 & 2.407 & 36.1 \\
\hline 6 & 141.37 & 0.01 & 1 & 1.269 & 41.2 \\
\hline 7 & 141.37 & 0.05 & 1.5 & 1.558 & 40.3 \\
\hline 8 & 141.37 & 0.1 & 2 & 1.877 & 39.9 \\
\hline 9 & 141.37 & 0.2 & 2.5 & 2.135 & 35.7 \\
\hline 10 & 141.37 & 0.3 & 0.5 & 2.256 & 33.4 \\
\hline 11 & 175.31 & 0.01 & 1.5 & 1.248 & 44.2 \\
\hline 12 & 175.31 & 0.05 & 2 & 1.558 & 44.5 \\
\hline 13 & 175.31 & 0.1 & 2.5 & 1.899 & 40.4 \\
\hline 14 & 175.31 & 0.2 & 0.5 & 1.746 & 39.1 \\
\hline 15 & 175.31 & 0.3 & 1 & 2.285 & 37.3 \\
\hline 16 & 209.23 & 0.01 & 2 & 1.221 & 45.1 \\
\hline 17 & 209.23 & 0.05 & 2.5 & 1.551 & 44.2 \\
\hline 18 & 209.23 & 0.1 & 0.5 & 1.273 & 42.7 \\
\hline 19 & 209.23 & 0.2 & 1 & 1.734 & 40.3 \\
\hline 20 & 209.23 & 0.3 & 1.5 & 2.305 & 38.5 \\
\hline 21 & 243.16 & 0.01 & 2.5 & 1.185 & 44 \\
\hline 22 & 243.16 & 0.05 & 0.5 & 1.149 & 42.8 \\
\hline 23 & 243.16 & 0.1 & 1 & 1.221 & 43.8 \\
\hline 24 & 243.16 & 0.2 & 1.5 & 1.714 & 41.7 \\
\hline 25 & 243.16 & 0.3 & 2 & 2.318 & 38.5 \\
\hline
\end{tabular}

\section{Optimization software (modeFRONTIER)}

One of the objectives of this study is to design, optimize and simulate optimal multi-purpose optimization algorithms for this purpose, the results extracted in practice had been incorporated in modeFRONTIER. to obtain optimal results. It is multidisciplinary design optimization written and a multi-objective optimization to let easy coupling to dissimilar commercial computer aided engineering (CAE) tool. modeFRONTIER lets an environment, which provides designers and product engineers to integrate their different commercial computer aided engineering tools, such as computational fluid dynamics (CFD) finite element analysis, and CAD software. To implement optimization by modifying the value assigned to the input parameters, and calculating the outputs modeFRONTIER provides a GUI driven wrapper about the CAE tool.

The user handbook of modeFRONTIER explain how given problem can be handled [9]. The modeFRONTIER program can be linked to several programs most importantly Matlab, CATIA, Excel, ANSYS ABAQUS and Workbench.

In general, to understand the modeFRONTIER Figure 4 shows a simple example of design and optimization using this program. With modeFRONTIER three major steps are necessary for achieving the aim:

- parameterize the problem .

- Setting goals

- Choosing a Optimization Strategy

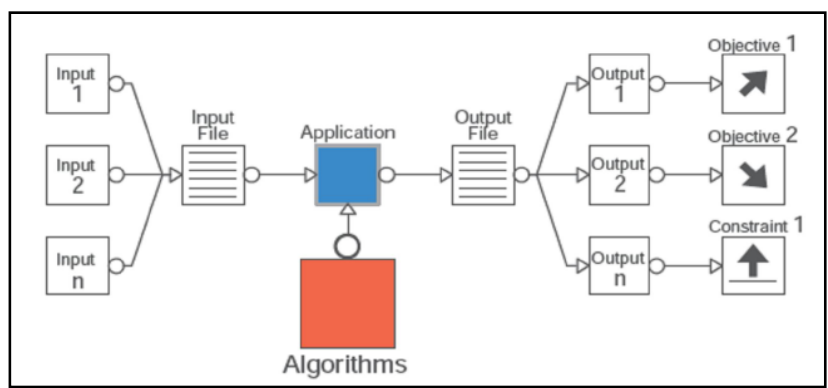

Fig. 4 General modeFRONTIER procedure of integration and optimization (modeFRONTIER ) [9].

\subsection{Multi-objective particle swarm optimization (MOPSO)}

A computer algorithm discovered by the social psychologist James Kennedy and the American electric engineer Russell Eberhart in 1995 as a matter of finding the maximum or minimum value based on experimentation and repetition[10]. The idea of the algorithm is the presence of a swarm of elements spread in a limited search area and move randomly to obtain the optimum solution in this region. In general, the greater the number of squadron elements and the smaller the search area, the easier and faster the solution will be found. The fewer elements and the search area, the less likely it is to obtain the optimum solution.

\section{Results and Discussions}

\subsection{Multiple regression models}

Transformation experiments were performed using the Taguchi method. An analysis was performed to determine the relationship between input factors and responses using Minitab 17 statistical program. Linear and quadratic regression was used and it was found that the quadratic regression was better based on $\mathrm{R} 2$ values. A mathematical 
model was developed to predict the roughness of the surface and the hardness of the metal as shown in Equations 1 and 2.

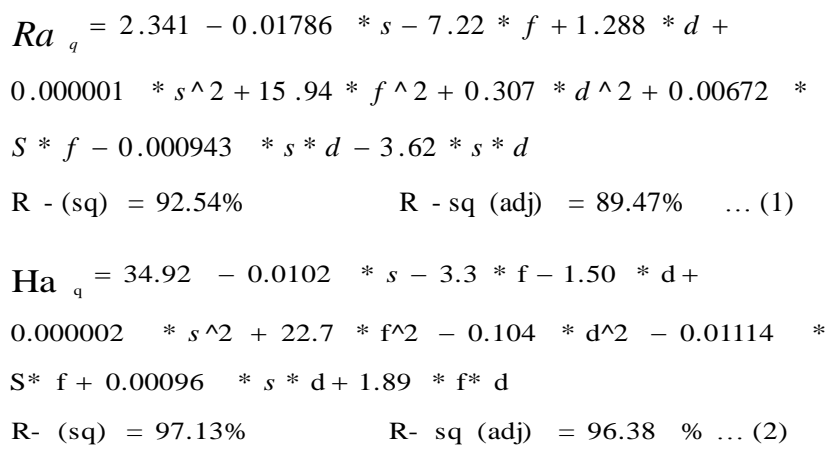

Where $s$ is the speed of cutting $(\mathrm{m} / \mathrm{min}), f$ is the feeding rate $(\mathrm{mm} / \mathrm{rev})$ and $d$ is the cutting depth ( $\mathrm{mm})$.

\subsection{Multi-object optimization}

a multi-regression model was used to develop a mathematical model that determines the relationship between inputs and outputs. The developed mathematical model has been converted to a function using the modeFRONTIER program. The upper and lower limits were determined by the parameters of the processing parameters and the number of variables were determined. Target function values were obtained to maximize material hardness and reduce surface roughness in CK1025 turning on CNC machine.

In the present work modeFRONTIER software is used for optimization in order to run process parameters. MOPSO parameters were selected during this study:

- Population size: 50,

- Number of iteration: 50,

- Crossover prob.: 0.9

- Mutation prob.: 0.1.

Figure 5 illustrates the formation of the Pareto front, through which we determine the optimum cutting conditions, which consist of the final set of solutions. The ideal front shape for Pareto is the result of the continuing nature of the problem of raised improvement. The figure shown is the result of the results entered into the MODIFONTER program depending on the variables entered and the response.

Figure 5 shows the Pareto solutions in dry operating condition using (MOPSO) the following figures explain the optimal Pareto solutions for the two functions where observe some of their relationships are conflict. This is due to the behavior of the function. These figures allow the designer or engineer more than one solution on the same figure.

Figures 6, and 7 represent the effect matrix of input parameters on the objective functions roughness of the surface ( $\mathrm{Ra}$ ) and hardness in negative and positive sign. From figure 6 , it is clear to observe that the parameter feeding rate (f) has the important influence on the $\mathrm{Ra}$ with

highest value (0.886) while the other parameters depth and speed ( $\mathrm{d}$ and $\mathrm{v}$ ) have the next impact on it.

From figure 7 , it is clear to notice that the cutting speed parameter $(v)$ has the significant effect on the hardness with highest value (0.807) while the other parameters feed and depth ( $\mathrm{d}$ and $\mathrm{f}$ ) have the next impact on it

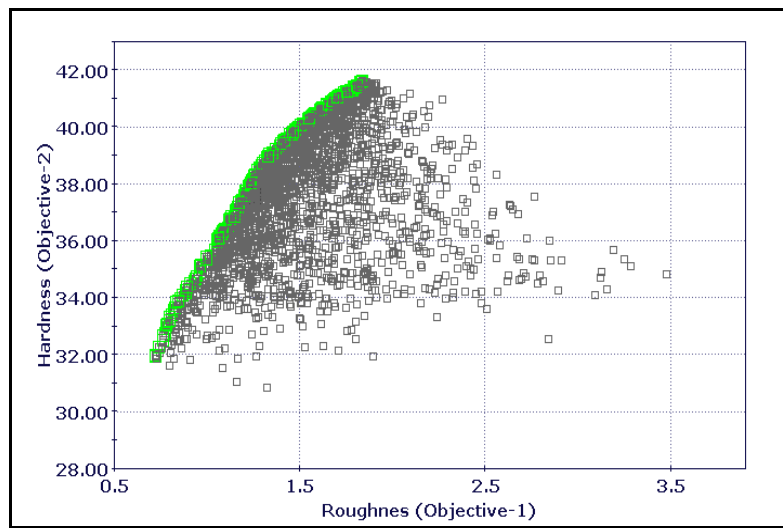

Fig.5 Pareto front by applying GA between hardness and surface roughness $(\mathrm{Ra})$.

\subsection{Confirmation experiments}

Through practical and theoretical results, the best five values were selected to verify the prediction of responses (Ha) and $\mathrm{Ra}$ ).Validation tests showed a good agreement with expected values of responses with less error from 10\% (Table 3).

Table 3 Validation experiment results based on multiobjective optimization.

\begin{tabular}{|l|c|c|c|c|c|c|}
\hline \multicolumn{1}{|c|}{$\begin{array}{c}\text { Optimum } \\
\text { values }\end{array}$} & \multicolumn{2}{|c|}{ Predicted } & \multicolumn{2}{c|}{ Actual } & \multicolumn{2}{c|}{ Error\% } \\
\cline { 2 - 7 } & Ha. & Ra & Ha. & Ra & Ha. & Ra \\
\hline $\begin{array}{l}107.44 \mathrm{~mm} / \mathrm{mi} \\
\mathrm{n}, 0.01 \mathrm{~mm} / \mathrm{rev}, \\
0.5 \mathrm{~mm}\end{array}$ & 35.18 & 1.318 & 35 & 1.282 & 0.51 & 2.7 \\
\hline $\begin{array}{l}141.37 \mathrm{~mm} / \mathrm{mi} \\
\mathrm{n}, 0.01 \mathrm{~mm} / \mathrm{rev}, \\
1 \mathrm{~mm}\end{array}$ & 36.04 & 1.348 & 35.5 & 1.269 & 1.49 & 5.8 \\
\hline $\begin{array}{l}175.31 \mathrm{~mm} / \mathrm{mi} \\
\mathrm{n}, 0.01 \mathrm{~mm} / \mathrm{rev}, \\
1.5 \mathrm{~mm}\end{array}$ & 37.50 & 1.332 & 36.5 & 1.248 & 2.66 & 6.3 \\
\hline $\begin{array}{l}209.23 \mathrm{~mm} / \mathrm{mi} \\
\mathrm{n}, 0.01 \mathrm{~mm} / \mathrm{rev}, \\
2 \mathrm{~mm}\end{array}$ & 39.56 & 1.255 & 39.5 & 1.221 & 0.15 & 2.7 \\
\hline $\begin{array}{l}243.16 \mathrm{~mm} / \mathrm{mi} \\
\mathrm{n}, 0.01 \mathrm{~mm} / \mathrm{rev}, \\
2.5 \mathrm{~mm}\end{array}$ & 42.22 & 1.224 & 41.5 & 1.185 & 1.7 & 3.1 \\
\hline
\end{tabular}




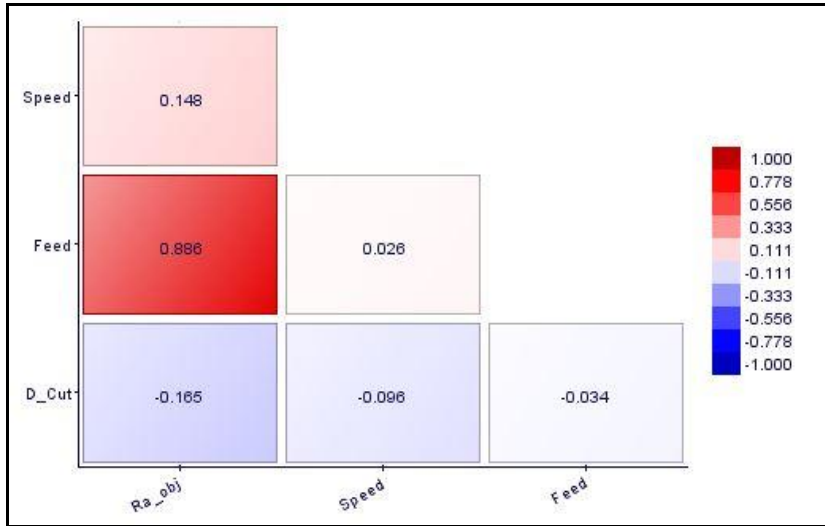

Fig. 6 matrix shows the effect of input parameters on Surface roughness .

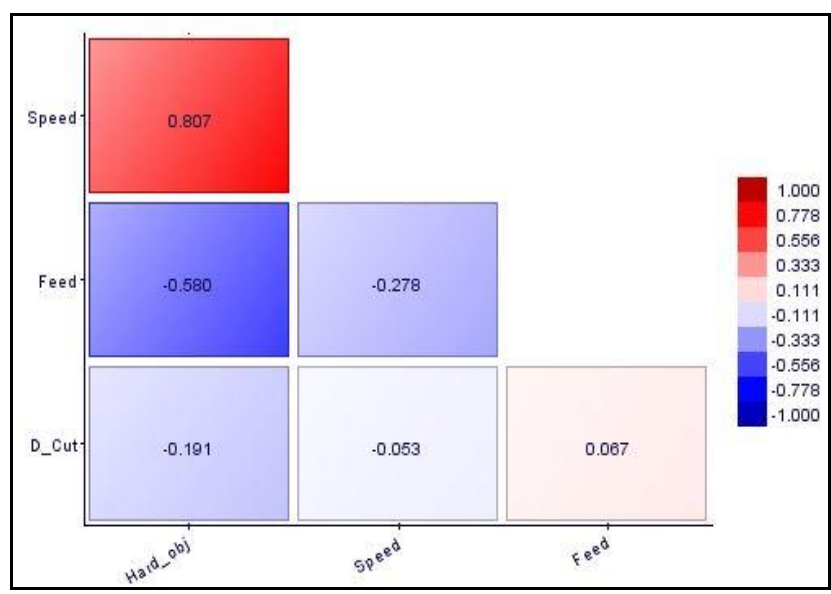

Fig. 7 matrix shows the effect of input parameters on hardness.

\section{Conclusions}

In this study, experiments were performed using the methodology of the Taguchi method. A regression analysis was performed to determine the relationship between input factors (cutting speed, feed rate and cut depth) and responses (surface roughness and hardness of the metal) using Minitab 17. The first general system model for the prediction of metal hardness and surface roughness was developed above the experimental area. Based on the multi-objective particle swarm optimization (MOPSO).

For the roughness of the surface, the lowest error ratio between the theoretical and practical results was obtained at $2.7 \%$ while the highest error ratio was $6.3 \%$. This indicates the accuracy of the solution obtained when comparing the theoretical and practical results. While For the hardness, the lowest error ratio between the theoretical and practical results was obtained at $0.15 \%$ while the highest error ratio was $2.66 \%$. This indicates the high accuracy of the extracted solution when comparing the practical and theoretical results.
From the effect matrix observe that the parameter feeding rate $(\mathrm{F})$ has the important influence on the Ra with highest value (0.886) while the other parameters depth and speed (D and V) have the next impact on it. While notice that the cutting speed $(\mathrm{V})$ has the significant effect on the hardness with highest value (0.807) while the other parameters feed and depth (D and F) have the next impact on it.

\section{References}

[1] H. E. Radhi, Sadiq Muhsin Almosawy and Hayder abdulhassan Lafta, 2015, "Multi-objective optimization in turning of aluminum", Firstconference for engineering sciences and technology.

[2] E. A. Rahim, S. Hassan, A. Saparudin, K. Kamarudin, and S. Thamizhmanii, (2007), "Tool Wear and Surface Roughness in Turning AISI 8620 using Coated Ceramic Tool", Proceedings of the World Congress on Engineering, Vol. II.

[3] Palanikumar K., (2007), "Modeling and analysis for surface roughness in machining glass fiber reinforced plastics using response surface methodology", Materials and design, Vol. 28, pp. 2611-2618.

[4] Saravankumar, K., Kumar, M. R., \&ShaikDawood, A. K. 2012, "Optimization CNC turning process parameters on INCONEL 718 using genetic algorithm”, Int. J. of Sci. \&Tech.,Vol.2,No.4,http://estij.org/papers/vol2no42012/1v ol2no4.pdf.

[5] N. Satheesh Kumara, Ajay Shetty, Ashay Shetty, Ananth K and Harsha Shetty, (2012), "Effect of spindle speed and feed rate on surface roughness of Carbon Steels in CNC turning", Procedia Engineering, Vol. 38.

[6] G. Harinath Gowd, S.SharmasVali, V.Ajay and G.Guru Mahesh, (2014), "experimental investigations and Effets of cutting variables on MRR and Tool wear For AISI S2 Tool steel", Elsevier:procedia material science 5(pp.1398-1407).

[7] Murat S. and Abdulkadir G., (2014), "Taguchi design and response surface methodology based analysis of machining parameters in CNC turning under MQL", Journal of Cleaner Production, Vol. 65.

[8] R. Hameed and H. Maath, (2017), "Optimization of Sustainable Cutting Conditions in Turning Carbon Steel by CNC Machine", Master's thesis, University of Thi Qar Engineering Sciences [9] Paulo, Davin J., Gaitonde, V.N., "Investigation into the effect of cutting condition on surface roughness in turning of free machining steel by ANN model" J. of Mat. Proc. Tech. 205(208) 16-32.

[10] Matthew Settles, (2005), "An Introduction to Particle Swarm Optimization", Department of Computer Science, University of Idaho, Moscow, Idaho U.S.A 83844 November 


\section{NOMENCLATURES}

$\mathrm{Ha}$

hardness

$\mathrm{Ra}$

Arithmetic average roughness

MRR

Metal removal rate

$\mathrm{Rz}$

Ten - point height

s

Cutting speed

f

Feeding rate

d

Depth of cut 